\title{
효과적인 개발협력을 위한 글로벌 파트너십 출범과 시민사회의 과제 : Post-Busan 이행체제에서의 시민사회의 발전방안
}

이 성 훈 (한국인권재단 상임이사 / KoFID 국제위원장)

\section{목 차}

1. 서론

2. 부산 글로벌 파트너십 출범의 의의와 한계

3. 국제시민사회의 부산 파트너십 이행 활동, 전략과 과제

4. 한국시민사회의 부산 파트너십 이행 활동, 전략과 과제

5. 결론

\section{1. 서론}

지난 6월 28-29일 파리의 유네스코본부에서 열린 OECD의 원조효과작업반(WP-EFF) 회의 참가자는 “효과적인 개발협력을 위한 글로벌 파트너십” Global Partnership for Effective Development Cooperation, GPEDC)” 출범에 합의하였다. 그리고 부산 파트너십 이행 모니 터를 위한 10 개의 지표를 채택하였다. 이로써 작년 12 월 1일 “효과적인 개발협력을 위한 부산 파트너십”과 정치선언문을 채택한 부산 세계개발원조총회의 구체적인 결실이 맺어졌다. 부산 총회를 개최한 한국정부는 $\mathrm{GPEDC}$ 의 집행위원회 공여국 대표의 일원으로 선출되어 향후에도 국제개발협력 정책에 적지 않은 영향력과 리더십 역할을 행사할 수 있게 되었다.

이번 파리 회의는 원조효과작업반의 마지막 회의로 앞으로는 GPEDC가 확대 보완하는 방식 으로 그 역할과 기능을 대치하게 되었다. 원조효과작업반은 MDG 여덟번째 목표인 개발을 위한 
글로벌 파트너십 이행을 위해 2003년 출범한 이래 2003년 로마, 2005년 파리, 2008년 아크라 그리고 마지막으로 2011년 부산총회까지 네 차례의 고위급회의를 개최하고 그 역사적 소임을 다한 셈이다. 마지막 회의를 $\mathrm{OECD}$ 본부가 아닌 유네스코에서 개최한 것은 UN과의 협력을 강 조하기 위한 것이었다. 게다가 회의 개막식에 반기문 UN 사부총장과 앙겔 구리야 $\mathrm{OECD}$ 사무 총장은 영상 축하 메시지를 보내 $\mathrm{GPEDC}$ 가 $\mathrm{UN}$ 과 $\mathrm{OECD}$ 의 공동 사업이라는 정치적 메시지를 강하게 전달하였다.

부산총회 이후 국제시민사회는 부산총회 후속 특히 포스트 부산 임시그룹 (Post-Busan Interim Group) 회의에 적극적으로 참여하여 GPEDC의 구성과 역할 그리고 부산 파트너십 이행을 위한 지표 내용 등에 대해 다양한 의견을 개진하였다. 부산총회에서 국제시민사회를 대 표한 두 네트워크인 Better Aid와 시민사회 개발효과성을 위한 오픈 포럼(Open Forum)은 지 난 2월 21-23일 필리핀 세부에서 부산총회 결과에 대한 평가를 바탕으로 향후 단일 조직으로 활동하기로 결정하고 이를 위한 준비논의를 진행하고 있다.

한국시민사회는 부산총회 직후 부산 파트너십을 효과적으로 국내에서 이행하기 위한 다양한 활동을 전개해왔다. 그리고 이번 원조효과작업반 회의 뿐 만 아니라 리우 +20 , UN 개발협력포 럼(UNDCF) 등 관련 국제회의 참여를 통해 국제개발협력의 중장기적 비전과 전략을 마련하고 있다. 한편 부산 파트너십을 국제적으로 실천하기 위해 개발효과성을 위한 시민사회 파트너십 (CSO Partnership for Development Effectiveness, $\mathrm{CPDE}$ ) 준비 과정과 아시아 특히 동북 아시아 차원의 시민사회 협력 체제를 구축하기 위한 다각적 노력을 전개하고 있다.

이 글은 $\mathrm{GPEDC}$ 출범의 의의와 한계를 시민사회의 관점에서 파악하고 GPEDC 관련 시민사 회의 역할과 활동 및 향후 과제를 제시하고자 한다. 특히 부산 파트너십을 이행하기 위한 국제 및 국내 시민사회의 전략과 활동을 소개하고 이와 관련한 도전과 과제를 제시하고자 한다.

\section{2. 부산 글로벌 파트너십 출범의 의의와 한계}

GPEDC는 부산총회를 계기로 형성된 정치적 모멘텀을 제도화한 것으로 부산 파트너십 이행 관련 책무성을 강화하고 모니터하는 중심적 역할을 수행할 예정이다. 이를 위한 운영체제로 1년 반 또는 2년에 한번 개최하는 장관급회의와 연2회 열리는 집행위원회(Steering Committee) 
그리고 OECD-UNDP 공동 사무국을 설치하기로 합의하였고1), 이행 전략으로 글로벌 모니터 링 지표가 채택되었다2).

$\mathrm{GPEDC}$ 의 출범은 여러가지 측면에서 국제개발협력의 담론과 거버넌스 역사에서 새로운 이정 표를 제시하였다는 평가를 받고 있다. 시민사회의 관점에서 볼 때 $\mathrm{GPEDC}$ 는 다음과 같은 특성 과 의의를 지닌다고 볼 수 있다.

첫째, 국제개발협력 역사에서 처음으로 시민사회를 포함한 다양한 이해당사자가 참가한 협력 체제가 만들어졌다. 다른 분야와 마찬가지로 개발협력을 다루는 $\mathrm{UN}, \mathrm{OECD}$ 등 거의 모든 국제 기구는 정부간 회의체 성격으로 운영되어 왔다. 그러나 GPEDC는 다자주의(Multilateralism) 형식을 탈피하여 다자간 이해당사자(Mult-stake holders)의 협력을 공식화한 첫 사례이다. 즉 실제 영향력에서는 차이가 있지만 형식에서는 정부, 국제기구, 시민사회, 기업, 의회, 지방정부 가 ‘동등한' 참여의 기회를 가지고 실질적으로 운영에 참여하는 틀이 만들어진 것이다. 이는 현 재 UN의 협의자격(consultative status) 제도와 92년 리우 환경과 개발회의에서 도입된 주요 그룹(Major Group)과 같은 이해당사자 참여 제도보다 질적으로 크게 진전된 것으로 평가받고 있다. 이는 개발협력의 양과 영향력에서 주요 행위자로 등장한 비국가행위자(기업, 시민사회 등)의 정치적 역할을 인정한 것으로 이 모델이 성공할 경우 다른 분야의 글로벌 거버넌스에도 적지 않은 파급효과가 있을 것으로 예상된다.

둘째, UN과 OECD 협력의 제도화이다. 2000년대 초반 MDGs 체제가 출범하면서 UN과 $\mathrm{OECD}$ 는 MDG 8번 글로벌 파트너십의 주요 의제인 ODA와 국제개발협력을 둘러싸고 서로 경 쟁하는 모습을 보여왔다. UN은 2002년 개발재원을 위한 몬트레이 합의를 통해 원칙과 행동계 획을 만들었고 2008년 도하에서 이의 이행 평가 회의를 개최하였다. 그리고 2008년 출범한 $\mathrm{UN}$ 개발협력포럼(DCF)은 개발협력 관점에서 $\mathrm{MDGs}$ 의 이행을 모니터하고 정책을 공유 및 조 율하는 역할을 수행해왔다. 한편 $\mathrm{OECD}$ 의 원조효과작업반은 같은 시기에 2003 년 원조조화 로 마선언과 2005년 원조효과성에 대한 파리선언, 2008년 아크라행동강령(AAA)을 주도하였다. 전통적인 공여국 중심의 $\mathrm{OECD}$ 는 일부 국가에 참여가 제한되어 대표성이 부족하고, 공여국과

1) Post-Busan Interim Group (PBIG), PROPOSED MANDATE FOR THE GLOBAL PARTNERSHIP FOR EFFECTIVE DEVELOPMENT CO-OPERATION (DCD/DAC/EFF(2012)7/REV1)

2) Post-Busan Interim Group (PBIG), PROPOSED INDICATORS, TARGETS AND PROCESS FOR GLOBAL MONITORING OF THE BUSAN PARTNERSHIP FOR EFFECTIVE DEVELOPMENT CO-OPERATION (DCD/DAC/EFF(2012)8/REV1) 
수원국 포함 모든 국가가 참여하는 UN은 대표성은 있지만 다양한 이해관계의 충돌로 실효성이 부족하다는 비판을 받아왔다. 이러한 이유로 인해 두 조직 모두 정당성의 위기를 겪어왔는데, $\mathrm{GPEDC}$ 출범을 계기로 효과성 증진을 통해 정당성을 강화가 구축되었다고 본다.

이를 계기로 그 동안 $\mathrm{OECD}$ 와 $\mathrm{UN}$ 으로 양분되었던 국제시민사회의 개발협력 관련 활동을 통 합적으로 전개할 수 있는 환경이 조성되어 보다 통합적인 애드보커시 전략이 마련될 것으로 예 상된다. 특히 대표성이 있는 UN에서의 시민사회의 참여가 옵서버 자격이었던데 반해, GPEDC 에서는 참가자 자격으로 참여가 가능해 시민사회의 입장에서는 영향력을 행사할 수 있는 보다 우호적 환경이 만들어졌다는 장점이 있다.

셋째, 10 개의 포괄적인 이행 지표를 통한 책무성강화 가능성 제고이다. 이번에 채택된 10 개 의 지표는 기존의 파리선언 이행지표 보완과 함께 새롭게 시민사회, 민간기업 그리고 젠더 부분 이 추가되었다. 이는 책무성이 공여국과 수원국 정부의 상호책무성(mutual accountability)을 넘어 개발협력의 모든 행위자 특히 시민사회와 민간기업의 책무성을 포함하는 다차원적 책무성 (multiple accountability)으로 확대되었다는 것을 의미한다. 이를 통해 개발원조의 책무성이 비국가행위자와 수혜자이자 주체인 개발현장의 주민을 대상으로 확대되었다고 볼 수 있다. 특 히 10 개의 지표 이외에도 부산 파트너십을 이행하는 전략으로 국제원조투명성조치(IATI)와의 협력을 강조한 계획을 채택한것 또한 원조정책의 투명성과 책무성을 높이는데 큰 기여를 할 것 으로 예상한다. ${ }^{3)}$

이러한 긍정적 의의에도 불구하고 $\mathrm{GPEDC}$ 는 시민사회의 관점에서 볼 때 적지 않은 한계와 도전에 직면하고 있다고 보여진다.

첫째, BRICS로 대표되는 신흥공여국의 소극적 참여 또는 불참이다. 현재 $\mathrm{GPEDC}$ 의 공동의 장으로 공여국, 수원국, 신흥국을 대표하여 영국, 나이지리아, 인도네시아의 장관급 인사가 선 임되었다. UN 반기문 사무총장은 지난 5월 카메론 영국 총리, 유도요노 인도네시아 대통령, 엘 렌 존슨 설리프 라이베리아 대통령을 '2015년 이후 국제개발을 위한 고위급 패널의 공동의장 (Co-chairs for High Level Panel on Global Development beyond 2015)'으로 위촉하였 다. 영국과 인도네시아는 $\mathrm{GPEDC}$ 공동의장국을 겸하게 되어 2015년 이후의 개발의제 설정과

3) Working Party on Aid Effectiveness, MEETING THE BUSAN COMMITMENT ON TRANSPARENCY Proposal for a common, open standard (DCD/DAC/EFF(2012)9) 
$\mathrm{GPEDC}$ 가 정치적으로 보다 긴밀히 연결될 것으로 예상된다. 그러나 비 $\mathrm{OECD}$ 국가로 남남협 력을 주도해 온 BRICS 국가 중 현재 GPEDC 참여 의사를 표명한 나라는 남아공이 유일하다. 중국, 인도, 브라질, 러시아는 참관은 하고 있지만, 공식참여 여부는 아직 불투명하다.

지난 리우+20에서 미국, 영국, 독일 정상의 불참에서 드러났듯이 미국과 유럽의 계속되는 경 제위기로 $\mathrm{OEDC} \mathrm{DAC}$ 국가의 국제개발협력 예산이 동결 또는 축소되면서 국제개발협력에 대한 정치적 의지가 약화되고 있다는 우려가 높아지고 있다. 그러나 BRICS 또한 자국의 이익을 추구 할 뿐 기존에 수립된 국제적인 규범을 적극적으로 실행하고 주도적으로 발전시켜 나가고자 하 는 의지를 보이지 않고 있다. 이러한 상황에서 국제개발협력은 리더십을 발휘하는 국가가 없어 한동안 표류할지 모른다는 우려가 일각에서 제기되고 있다. 과연 GPEDC가 이러한 도전을 극 복하고 명칭대로 모든 국가가 참여하는 효과적인 개발협력을 위한 글로벌 파트너십으로 성공적 으로 안착할지 여부는 현재로서는 미지수이다.

둘째, 약화되는 국제규범과 책무성의 문제이다. OECD DAC 국가 중심으로 2005년 만든 원 조효과성에 대한 파리선언 이행에 대한 2011년 평가에 따르면 대다수의 국가가 대다수의 영역 에서 만족할 만한 성과를 이루지 못하였다. MDGs와 마찬가지로 국제사회가 자발적으로 이행 하기로 합의한 약속이 충실하게 지켜지지 않은 것이다. 그러나 부산회의에서 이에 대한 철저한 원인 분석과 반성 및 대책마련 없이 새로운 파트너십이 출범하였다. 따라서 시민사회 일부에서 는 GPEDC도 전과 마찬가지로 공약(空約)에 그치고 말 것이라는 비판을 제기하고 있다.

작년 부산총회는 중국을 비롯하여 남남협력을 중시하는 신흥공여국을 끌어들이기 위해서 기 존의 국제규범을 약화시켰다는 시민사회의 비판이 적지 않았다. ${ }^{4)}$ 이러한 상황에서 비록 10 개 지표의 내용이 매우 포괄적이고 파리선언에 비해 진일보했다는 평가를 받았지만 Global light, country focused 원칙하에서 자발성이 강조되어 구속력은 오히려 약화되었다는 평가를 받고 있다. 즉 지표에서 책무성이 형식적으로 확대되고 심화되는 것처럼 보이지만 실질적으로 약화 되고 있다는 것이다. 이러한 경향은 리우 +20 등 최근 개최된 대부분의 국제회의에서 공통적으 로 나타나는 현상으로 UN의 지도력 약화와 맞물리면서 당분간 지속될 것으로 시민사회는 우려 하고 있다.

4) 부산 총회 선언문 제2항의 "부산에서 합의된 결과문서의 원칙, 약속과 행동은 자발적인 원칙하에 남남협력 참여주 체의 참고가 되어야 할 것이다(The principles, commitments and actions agreed in the outcome document in Busan shall be the reference for South-South partners on a voluntary basis)."라는 표현 수용여부는 시민사회 입장에서 부산총회 전체의 정당성을 인정하느냐 마느냐의 중대한 문제였다. 
셋째, $\mathrm{GPEDC}$ 내에서의 시민사회의 영향력 한계이다. GPEDC에 동등한 참가자로서 참여하 게 된 것은 국제 시민사회에 새로운 기회임이 분명하다. 이는 그동안의 수많은 노력의 결실로 긍정적 성과로 평가받아 마땅하다. 그러나 과연 시민사회가 집행위원회의 정식 멤버로 참석한 다는 것의 의미와 효과성에 대한 의문이 여전히 가시지 않고 있다. 부처간의 이해와 입장 차이 에도 불구하고 대외적으로 구속력있는 단일한 입장을 취하는 국가와 달리, 시민사회는 자발성 과 다양성을 속성으로 하는 구조적 특성으로 인해 단일한 입장을 취하는 것이 현실적으로 어렵 고, 설사 단일한 입장을 취해도 그 구속력과 실행력은 국가와 달리 매우 자의적이고 가변적이 다. 집행위원회 참여를 통해 의사결정 관련 정보에 대한 접근성과 의사결정 과정에서의 영향력 행사라는 측면에서는 분명 장점이지만 시민사회 내부의 효과 특히 결정 이후의 실행 효과성은 여전히 의문으로 남아있다.

부산총회 기간중에도 드러났듯이 단일한 입장을 표명해야 한다는 안팎의 요구로 인해 시민사 회의 다양성과 자발성이 약화되고 획일성이 커지는 역효과가 나타나기도 했다. 그리고 회원 단 체의 개별 국가정부에 대한 로비 보다는 시민사회 대표의 로비 전략과 역량에 의존하는 행태, 그리고 실제 $\mathrm{GPEDC}$ 에 참여하는 시민사회 대표와 일국적 그리고 현장 사업 단체의 정보 격차 와 시각차는 여전히 큰 도전으로 남아있다. 그리고 시민사회 내부에서 단일한 입장을 취하기 위 해 다양한 이해관계와 입장을 조율 및 조정하는데 드는 시간과 비용을 고려할 때 비용 대비 효 과성의 문제 또한 간과할 수 없다.

그리고 정부대표가 대다수를 차지하고 있는 GPEDC 안에서 과연 한 자리의 시민사회 대표가 얼마나 정치력을 발휘해서 시민사회의 입장을 반영할 수 있을지도 의문이다. 지난 달 원조효과 작업반 회의에서 드러났듯이 두 자리를 요구한 시민사회의 주장은 별다른 지지를 얻지 못했고 이에 대해 시민사회 대표자는 상징적 항의를 하는데 그치고 말았다. GPEDC의 역할과 성과가 시민사회의 기대에 미치지 못하거나 시민사회의 핵심가치에 반하는 정책이 만들어지고 이에 대 해 시민사회 대표가 제대로 역할을 하지 못할때 과연 시민사회는 어떤 입장을 취해야 하는가라 는 우려가 벌써 일각에서 제기되고 있다. 특히 이런 입장은 애초부터 대표성을 지닌 UN이 아니 라 $\mathrm{UN}$ 의 정당성을 약화시키려는 의도로 시작된 $\mathrm{OECD}$ 의 원조효과성 담론과 정책에 시민사회 가 들러리를 서서 명분을 제공했다는 비판을 했던 일부 시민사회로부터 꾸준히 제기되고 있다. 


\section{3. 국제시민사회의 부산 파트너십 이행 활동, 전략과 과제}

국제시민사회는 2008년 아크라 회의를 계기로 원조효과성 논의에 본격적으로 참여하였다. 아크라행동강령(AAA) 제 20 항목은 시민사회를 스스로의 권리를 지닌 독립적인 개발 행위자로 인정하였고 부산총회 결과문서 제 22 항에서는 시민사회의 역할로 국가의 역할을 보완하는 현장 개발사업 뿐만 아니라 개발정책 수립과 감시를 하는 애드보커시 활동을 강조하였다. GPEDC에 시민사회 대표가 국가와 동등한 자격으로 참여하게 된 것은 이러한 시민사회의 위상과 역할 강 화의 맥락에서 이루어진 것으로 볼 수 있다.

$\mathrm{GPEDC}$ 의 출범과 함께 국제 시민사회의 활동은 크게 대외적으로 $\mathrm{GPEDC}$ 의 참여와 대내적 으로 시민사회의 개발효과성 증진으로 구분할 수 있다. 전자가 애드보커시 영역이라면 후자는 스스로의 책무성 증진이라고 할 수 있다. 이 두 가지 역할은 상호보완적이며 서로를 강화시켜주 는 특성을 지니고 있다. GPEDC 출범 이후 국제 시민사회의 활동은 아래와 같은 내용과 방향 에서 전개되고 있다.

첫째, GPEDC 집행위원회의 참여이다. 18 명으로 구성된 집행위원회는 3 명의 공동의장을 포 함하여 정부대표가 12 명, 국제기구대표가 3 명 그리고 시민사회, 민간기업 및 의회대표 3 명으로 구성되어 있다.5) 현재 Better Aid의 공동대표가 임시로 시민사회를 대표하고 있지만 올해 10 월 $\mathrm{CPDE}$ 가 출범하면서 선출될 새로운 공동대표가 공식적으로 참여할 예정이다.

현재 국제시민사회는 시민사회의 다양성과 기여를 고려해서 집행위원회 공동의장직과 추가로 집행위원회 한자리를 더 요구하고 있다. 그 결과에 상관없이 현재 집행위원회는 정부대표가 절 대 다수를 차지하고 있지만 시민사회는 이슈에 따라 캐스팅 투표는 아니더라도 유사한 입장을 취하는 정부 및 다른 대표와 연대하여 의사결정에 적지 않은 영향력을 행사할 수 있는 가능성이 적지 않다고 본다.

둘째, 시민사회는 부산총회에서 합의한 기존의 8개 빌딩블록(Building Blocks) ${ }^{6}$ ) 이외에도

5) 정부대표는 다시 공여국 4, 수원국 7 (이중 한자리는 취약국가를 대표하는 $g 7+$ ), 신흥공여국 2로 구성되며, 국제 기구는 $\mathrm{OECD} \mathrm{DAC}$ 의장, $\mathrm{UNDP}$, 다자간은행(MDB) 대표로 구분된다. 상대적으로 전통적인 공여국이 수적으로 소수이다. 
새로운 빌딩블록을 만드는데 적극적으로 참여하고 있다. 국제노동조합연맹(ITUC)은 민간기업, 국제투명성 본부는 투명성 빌딩블록 등 시민사회내의 단체별 전문성과 우선순위에 따라 참여하 고 있다. 새로운 빌딩블록 주제 가운데 인권에 기반한 접근(RBA)은 시민사회 입장에서 개발효 과성 증진의 핵심 이슈이기에 가장 많은 단체가 참여하고 있다. 빌딩블록은 관심있는 국가와 기 구 및 단체들이 자발적으로 추진하는 것이지만 내용적으로 GPEDC의 정책의제 특히 모니터링 지표와 긴밀한 연관이 있어 시민사회의 입장에서는 중요한 활동영역으로 간주되고 있다.

셋째, 10 개 지표7) 중 시민사회 관련된 지표의 개발이다. 시민사회 지표는 부산선언문 제 22 항8)에 따른 것인데, 보다 구체적으로는 시민사회가 개발에의 참여와 기여를 극대화하는 환경에서 활 동하는것 즉 시민사회의 개발효과성을 가능케하는 우호적 환경(enabling environment)에 관 한 것이다. 시민사회 관련 지표는 민간기업과 젠더 관련 지표와 함께 이번에 새롭게 추가된 것 으로 시민사회의 요청에 의한 것이었다. 그러나 현재 국제적으로 통용되는 시민사회 관련한 지 표가 없어 CIVICUS가 이미 개발한 시민사회 관련 지표를 토대로 추가 보완하기로 하였다. 지 표의 내용은 특히 시민사회의 활동을 위한 법적 행정적 규제의 틀과 시민사회의 활동에 직접적 영향을 주는 정치적 환경과 거버넌스의 주요 요소를 반영할 예정이다.

넷째, $\mathrm{CPDE}$ 출범을 통한 시민사회 조직의 확대 및 강화이다. 앞서 언급했듯이 부산총회 이전 에 Better Aid와 Open Forum으로 나누어 전개되어온 국제시민사회의 활동은 향후 $\mathrm{CPDE}$ 라 는 통합된 단일 조직의 틀 속에서 전개될 예정이다. 스웨덴 국제개발청(Sida)의 재정지원으로 부산총회에 참가한 단체를 중심으로 현재 지역별, 영역별로 $\mathrm{CPDE}$ 의 역할, 운영구조, 사업 방 향과 전략에 대한 협의가 진행 중이다.

다섯째, 이스탄불 원칙의 실천이다. 부산총회에서 공식인정을 받은 시민사회의 개발효과성 증진을 위한 이스탄불 원칙은 이제 개발협력 분야 시민사회단체가 자발적으로 만든 공통의 기

6) 8 개 빌딩블록은 성과와 책무성, 투명성, 다양성과 분절화, 남남협력과 삼각협력, 취약국가, 기후변화재원, 효과적인 제도와 정책, 민간기업이다.

7) 10 개 지표는 수원국의 우선순위 반영(1), 시민사회의 참여와 기여(2), 민간분야의 역량강화(3), 개발협력에 관한 정 보공개(4), ODA 예산 단기 및 중기 예측 가능성 (투명성)(5), 모든 개발원조의 예산화(6), 상호책무성 검토 참여(7), 성평등과 여성 역량강화에 대한 공공지출(8), 수원국 시스템 활용 및 개도국 역량강화(9), 비구속화(10)로 구성되어 있다.

8) [we will] "implement fully our respective commitments to enable CSOs to exercise their roles as independent development actors, with a particular focus on an enabling environment, consistent with agreed international rights, that maximises the contributions of CSOs to development." 
준이자 규범으로 자리잡았고, 현장에서의 실행을 위한 프레임워크와 이행 가이드라인인 툴킷을 제작하여 보급하고 있다. 이스탄불 원칙은 시민사회의 관점에서 기존의 MDGs, 파리선언의 원 조효과성 원칙 및 인권에 기반한 접근(RBA)의 핵심 원칙을 통합적으로 수용하여 체계화 한 것 으로 시민사회의 책무성과 효과성 증진에 전략적인 도구역할을 수행할 것으로 예상된다.

위에서 언급한 다양한 활동을 전개하고 있는 국제시민사회단체는 대내외적으로 몇가지 도전 과 과제에 직면해있다.

첫째는 $\mathrm{CPDE}$ 체제하에서 글로벌 애드보커시와 현장 사업단체 간의 유기적 결합과 시너지 효 과 창출 가능성이다. GPEDC의 성격상 시민사회 내에서 Better Aid를 주도적으로 이끌어온 정 책 애드보커시 중심의 단체가 계속해서 $\mathrm{CPDE}$ 내에서의 리더십 역할을 수행할 것으로 예상한다. 그리고 이스탄불 원칙과 이행을 위한 프레임워크를 만드는데 주력해 온 Open Forum의 주요 단체는 상대적으로 국내적 실천에 더 주력할 것으로 보인다. 이 과정에서 현장 사업이 없이 정 책 애드보커시에 주력하는 단체와 현장 사업의 개발효과성 증진에 주력하는 단체 간에 $\mathrm{CPDE}$ 의 사업 방향을 둘러싼 긴장과 갈등이 예상된다. 부산총회 이전에 발생한 이러한 갈등요인은 부산 총회 이후에도 해소되지 않고 여전히 시민사회 내에 연대의 걸림돌로 작용하고 있다. 특히 특정 정치적 이념을 기반으로 노동과 여성단체가 주도해 온 기존의 Better Aid가 옥스팜과 월드비전 처럼 현장 사업을 토대로 애드보커시 활동을 수행하고 있는 기존의 개발협력 전문 단체를 포용 할지 아직 불투명하다.

둘째는 시민사회 개발효과성 증진을 위한 정부의 역할과 정부와의 파트너십이다. 시민사회 개 발효과성 증진을 위해서는 정부의 역할 특히 우호적 정책 환경(enabling environment)이 필 수적이다. 정부는 특히 시민사회가 정부의 감시 역할을 제대로 할 수 있도록 표현의 자유와 집 회 결사의 자유 보장, 시민사회 역량강화를 위한 지원 등 필요한 제반 법적 정책적 지원을 제공 해야 한다. 그러나 대다수의 국가 특히 개도국에서 시민사회의 정치적 공간은 지속적으로 축소 되고 있으며, 이는 시민사회 개발효과성의 최대 위협요소가 되고 있다. 부산총회에서 인정된 이 스탄불 원칙을 통해 시민사회 스스로의 책무성과 효과성 증진 노력은 큰 성과를 거두었지만, 이 의 지속가능성을 위한 우호적 환경 관련 정부의 책임에 있어서는 별다른 진전이 없었다. 따라서 시민사회 일각에서는 우호적 환경 개선이 없는 상황에서 시민사회의 이스탄불 원칙 강조는 오 히려 역효과를 불러 올 수도 있다는 우려를 표명하고 있다.

셋째는 $\mathrm{CPDE}$ 내의 새로운 리더십 창출과 운영에서의 투명성과 책무성 도전이다. 부산총회 직 
후 개최된 평가회의에서 부산총회 준비과정에서 나타난 Better Aid 리더십의 투명성 부족과 비 민주적 관행이 큰 논란을 불러 일으켰다. 그러나 이후 올해 2 월 열린 세부회의에서의 후속 평가 와 논의를 거치면서 시민사회 단체는 자체적으로 개선 대책을 마련하여 이러한 문제를 해결해 나가고 있지만 여전히 논란의 원인이 남아있어 보인다. $\mathrm{CPDE}$ 가 기존의 Better Aid 사무국과 몇몇 단체 중심의 운영이 아니라, 시민사회단체의 보다 광범위한 참여를 이끌어내기 위해서는 시민사회 내부의 관행을 획기적으로 개선할 필요가 있다.

\section{4. 한국시민사회의 부산 파트너십 이행 활동, 전략과 과제}

한국시민사회는 개도국에서 현장 사업을 수행하는 단체를 기반으로 구성된 해원협과 부산총 회를 계기로 출범한 국제개발협력시민사회포럼(KoFID)을 중심으로 부산 파트너십 이행과 관련 한 다양한 활동을 전개해왔다. 한국시민사회의 일부 단체는 2008년 당시 아크라 회의를 인지하 고 있었으나 역량과 관심 부족으로 직접 참여하지 못했고, 한국정부가 2011년 제4차 고위급회 의를 주최하기로 결정된 직후부터 국제시민사회의 원조효과성 관련 활동에 보다 본격적으로 참 여하기 시작하였다.

$\mathrm{GPEDC}$ 출범 이후 한국시민사회의 활동은 크게 GPEDC 참여와 국제시민사회와의 연대활동 그리고 부산 파트너십의 국내적 이행으로 구분할 수 있다.

\section{1) GPEDC참여}

한국의 시민사회 단체는 현재 GPEDC 집행위원회에 시민사회 대표로 참여하는 $\mathrm{CPDE}$ 공동 의장과 한국정부 대표의 두 채널을 통해 간접적으로 참여할 계획이다. 특히 한국시민사회는 특 정 주제나 사안에 대한 $\mathrm{CPDE}$ 의 입장을 정하는데 적극 참여할 필요가 있으며, 그 결과를 한국 정부 대표와 공유할 필요가 있다. 특히 연 2회 열리는 집행위원회를 전후로 사전 간담회와 사후 디브리핑을 정례화하여 보다 실질적인 협의의 장이 되도록 만들 필요가 있다.

\section{2) 빌딩블록 참여}

현재 한국시민사회는 역량과 재원부족으로 기존의 8개 빌딩블록 활동에 적극적으로 참여하지 
못하고 있다. 그러나 인권에 기반한 접근 $(\mathrm{RBA})$ 논의를 모니터하면서 꾸준히 참여해왔다. 이에 비해 한국정부는 효과적인 제도와 민간기업 빌딩블록에 적극 참여하고 있고, 특별 이니셔티브 인 젠더를 주도적으로 이끌고 있다. 한국시민사회 단체는 분야별 전문성을 지닌 국제 시민사회 단체와의 전략적 연대를 통해 빌딩블록의 논의를 모니터하고 이에 대한 한국시민사회의 입장을 쳬계화 할 필요가 있다.

\section{3) 국제시민사회와의 연대 활동}

국제시민사회와의 연대활동은 크게 글로벌 차원에서의 $\mathrm{CPDE}$ 참여와 아시아 차원에서의 연 대로 구분할 수 있다. 전자와 관련하여 올해 10월 정식 출범할 예정인 $\mathrm{CPDE}$ 에 KoFID는 동북 아 지역대표로 참여할 예정이다. 후자와 관련해서는 2011년 9월 처음 개최된 서울시민사회포럼 $(\mathrm{SCSF})$ 과 올해 1월말 제2차 서울시민사회포럼 그리고 올해 9월 제3차 서울시민사회포럼의 지 속적 개최를 통해 아시아 특히 동북아 지역에서 개발협력분야 시민사회의 연대를 지속적으로 강화할 계획이다.

이 과정에서 부산총회 준비 과정에서 주도적 역할을 하지 못한 국가별 협의체(national platform)의 역할과 상호연대를 강화하여 부산 파트너십의 효과적인 국내 이행을 촉진할 계획 이다.

\section{4) 부산 파트너십의 국내 이행}

한국정부와 마찬가지로 한국시민사회는 부산 세계시민사회포럼(BCSF)의 주최단체로서 부산 파트너십 탄생에 산파역할을 하였다. 따라서 부산 파트너십을 국내적으로 충실히 이행하는 모 범을 보여야하는 도적적 책무감을 지니고 있다. 한국정부가 추진중인 ODA 선진화 방안을 부산 파트너십과 $\mathrm{OECD} \mathrm{DAC}$ 의 규범에 부합하는 방향에서 실행될 수 있도록 시민사회는 감시 및 견 인 역할을 적극적으로 수행할 필요가 있다. 이와 관련된 구체적인 과제로 다음과 같은 제안을 하고자 한다.

첫째, 10 개의 글로벌 모니터링 지표를 국내의 상황에 맞게 개발하여, 이를 국내 개발협력 정 책의 질을 제고하는데 전략적으로 활용하여야 한다. 현재의 10 개 지표는 일종의 예시이자 가이 드라인으로 각 국가의 정부는 자국의 현실에 적합한 지표를 만들 것을 요구받고 있다. 부산 파 트너십 이행을 위한 한국적 지표 개발에 시민사회는 적극 참여할 계획이고, 이 때 $\mathrm{OECD}$ 의 동 
료평가(Peer Review)의 권고안을 보다 적극적으로 수용 및 적용해야 한다.

둘째, 이스탄불 원칙과 같이 한국시민사회를 포함하여 국제시민사회가 공동으로 그리고 자발 적으로 개발한 시민사회 개발효과성 원칙을 충실히 이행하여야 한다. 해원협은 지난 7월 말 코 이카의 지원으로 이스탄불 원칙 이행 툴킷을 번역 출간하였고, 이의 실행을 위한 워크샵을 조직 하였다.

셋째, 지난 6 월 총선에 따라 출범한 제 19 개 국회와 12 월 대선 캠페인 과정에서 국제개발협력 을 정책의제로 제기하여 국민적 관심사와 개선의 계기로 삼을 필요가 있다. 부산총회는 국제개 발협력에서 국회의 역할을 처음으로 명시적으로 언급하였다. GPEDC의 집행위원회에 의회대 표가 동등하게 참여하게 된 것은 국회의 역할을 강화하기 위한 포석으로 보인다.

\section{5. 결론}

앞에서 강조했듯이 GPEDC의 출범은 한국 및 국제시민사회에 새로운 기회이자 도전이다. 식 량, 에너지, 금융, 기후변화 등 악화되는 지구적 차원의 복합위기에 직면한 국제사회는 그 어느 때보다 효과적인 개발협력을 요구하고 있다. 갈수록 높아지는 외부적 요구에 부응하여 한정된 재원을 효과적으로 활용하여 사업의 개발효과성을 제고해야 하는 시민사회는 중장기적인 종합 전략을 필요로 하고 있다.

특히 국제규범에 부합하면서 동시에 한국적 특성이 살아있는 국제개발협력 정책과 관행을 만 들어 부산총회 주최 국가로서의 도덕적 정치적 책무성을 성실하게 수행하는 모범을 보일 필요 가 있다. 이를 위해서는 한국정부와 시민사회 그리고 민간기업, 국회, 지방정부 등 모든 국제개 발협력 행위자가 참여하는 효과적인 파트너십 체제를 국내에서 구축할 필요가 있다. 이 과정에 서 UN과 OECD DAC 특히 부산 파트너십 등 국제기준과 규범을 체계적으로 숙지하고 이를 국 내에 효과적으로 실천하고자 하는 자세가 우선적으로 요구된다. 그리고 이러한 모범적 실천을 토대로 보다 높은 수준의 국제규범과 정책을 만드는데 앞장서서 의제설정과 규범제정자로서의 역할을 강화할 필요가 있다. 


\section{참고문헌}

\section{1. 국내문헌}

국제개발협력시민사회포럼(KoFID) "부산 세계개발원조총회(HLF-4)에 대한 입장과 정책제언 (포지션 페이퍼)", 2011년 8월

국제개발협력시민사회포럼(KoFID), “부산 세계시민사회포럼 (BCSF) 백서” 2012년 7월 박은하, “부산 세계개발원조총회 주요 성과 및 향후 과제” (2011, No 4) 한국국제협력단

손혁상 외. 2011.「개발효과성 제고를 위한 정부-시민사회 협력방안 연구」. KOICA 연구보고서. 한국국제협력단 (출판 예정)

손혁상, "부산개발원조총회(HLF-4)와 세계시민사회의 대응전략: BetterAid와 Open Forum을 중심으로”, 국제개발협력 (2011, No 3), 한국국제협력단

이성훈, "국제개발협력과 인권 : 부산 제4차 $\mathrm{OECD}$ 원조효과 고위급회의 (세계개발원조총회)와 한국의 역할” 국제개발협력 (2011, No 1), 한국국제협력단

이성훈, “민주주의와 국제개발협력 - 한국의 민주화 경험과 ODA”, 국제개발협력 (2011, No 3), 한국국제협력단

이성훈, “시민사회가 바라보는 부산총회의 성과와 향후 과제” 국제개발협력 (2011, No 4), 한국국제협력단

이성훈, “국제개발협력과 시민사회의 역할: 부산총회 이후의 맥락에서” 국제개발협력 (2012. No 1) 한국국제협력단

이태주, “부산 HLF-4 이후 한국의 과제: 시민사회의 관점", 부산. HLF-4이후의 세계원조체 계와 한국의 과제, 2011 국제개발협력학회 정기학술회의

임소진, "원조효과성에서 개발효과성으로” 국제개발협력 (2012. No 2), 한국국제협력단 


\section{2. 국외문헌}

Post-Busan Interim Group (PBIG), PROPOSED MANDATE FOR THE GLOBAL PARTNERSHIP FOR EFFECTIVE DEVELOPMENT CO-OPERATION (DCD/DAC/EFF(2012)7/REV1)

Post-Busan Interim Group (PBIG), PROPOSED INDICATORS, TARGETS AND PROCESS FOR GLOBAL MONITORING OF THE BUSAN PARTNERSHIP FOR EFFECTIVE DEVELOPMENT CO-OPERATION (DCD/DAC/EFF(2012)8/REV1)

Working Party on Aid Effectiveness, MEETING THE BUSAN COMMITMENT ON TRANSPARENCY - Proposal for a common, open standard (DCD/DAC/EFF(2012)9) 